\title{
Changes in cerebral oxygenation based on intraoperative ventilation strategy
}

This article was published in the following Dove Press journal:

Medical Devices: Evidence and Research

\section{Elisabeth Dewhirst ${ }^{1}$ \\ Hina Walia' \\ Walter P Samora ${ }^{2}$ \\ Allan C Beebe ${ }^{2}$ \\ Jan E Klamar ${ }^{2}$ \\ Joseph D Tobias ${ }^{1,3}$}

'Department of Anesthesiology and Pain Medicine, Nationwide Children's Hospital, Columbus, OH, USA;

${ }^{2}$ Department of Orthopedic Surgery,

Nationwide Children's Hospital, The

Ohio State University, Columbus, $\mathrm{OH}$,

USA; ${ }^{3}$ Department of Anesthesiology

and Pain Medicine, The Ohio State

University, Columbus, OH, USA
Correspondence: Elisabeth Dewhirst Department of Anesthesiology and Pain Medicine, Nationwide Children's Hospital, 700 Children's Drive,

Columbus, OH 43205, USA

Tel + I 6147224200

Fax +l 6147224203

Email Elisabeth.Dewhirst@

nationwidechildrens.org
Introduction: Cerebral oxygenation can be monitored clinically by cerebral oximetry (regional oxygen saturation, $\mathrm{rSO}_{2}$ ) using near-infrared spectroscopy (NIRS). Changes in $\mathrm{rSO}_{2}$ have been shown to precede changes in pulse oximetry, providing an early detection of clinical deterioration. Cerebral oximetry values may be affected by various factors, including changes in ventilation. The aim of this study was to evaluate the changes in $\mathrm{rSO}_{2}$ during intraoperative changes in mechanical ventilation.

Patients and methods: Following the approval of the institutional review board (IRB), tissue and cerebral oxygenation were monitored intraoperatively using NIRS. Prior to anesthetic induction, the NIRS monitor was placed on the forehead and over the deltoid muscle to obtain baseline values. NIRS measurements were recorded each minute over a 5-min period during general anesthesia at four phases of ventilation: 1) normocarbia $(35-40 \mathrm{mmHg})$ with a low fraction of inspired oxygen $\left(\mathrm{FiO}_{2}\right)$ of $\left.0.3 ; 2\right)$ hypocarbia $(25-30 \mathrm{mmHg})$ and low $\mathrm{FiO}_{2}$ of 0.3 ; 3) hypocarbia and a high $\mathrm{FiO}_{2}$ of 0.6; and 4) normocarbia and a high $\mathrm{FiO}_{2}$. NIRS measurements during each phase were compared with sequential phases using paired $t$-tests.

Results: The study cohort included 30 adolescents. Baseline cerebral and tissue oxygenation were $81 \% \pm 9 \%$ and $87 \% \pm 5 \%$, respectively. During phase 1 , cerebral $\mathrm{rSO}_{2}$ was $83 \% \pm 8 \%$, which decreased to $79 \% \pm 8 \%$ in phase 2 (hypocarbia and low $\mathrm{FiO}_{2}$ ). Cerebral oxygenation partially recovered during phase $3(81 \% \pm 9 \%)$ with the increase in $\mathrm{FiO}_{2}$ and then returned to baseline during phase $4(83 \% \pm 8 \%)$. Each sequential change (e.g., phase 1 to phase 2$)$ in cerebral oxygenation was statistically significant $(p<0.01)$. Tissue oxygenation remained at $87 \%-88 \%$ throughout the study. Conclusion: Cerebral oxygenation declined slightly during general anesthesia with the transition from normocarbia to hypocarbic conditions. The $\mathrm{rSO}_{2}$ decrease related to hypocarbia was easily reversed with a return to baseline values by the administration of supplemental oxygen (60\% vs. $30 \%)$.

Keywords: pediatric, cerebral oxygenation, near infrared spectroscopy (nirs), intraoperative, ventilation

\section{Introduction}

To optimize intraoperative care, it is imperative to maintain adequate cardiac output and delivery of oxygen to the tissues. Intraoperative care includes monitoring of blood pressure (BP) and systemic oxygenation (pulse oximetry); recently, interest has been placed on measuring end-organ tissue oxygenation. Near-infrared spectroscopy (NIRS) monitors are used to measure tissue oxygenation, and are becoming more commonly used in anesthesia practice. The NIRS monitor consists of a noninvasive adhesive sensor with a laser light source and two photodetectors. Using optical 
technology based on the relative absorption of infrared light by different hemoglobin species, the monitor generates a measurement of regional oxygen saturation $\left(\mathrm{rSO}_{2}\right) .{ }^{1}$ The device is typically applied to the forehead and used to measure cerebral oxygenation, but can be used to measure regional tissue saturation elsewhere in the body. Data in both the adult and pediatric literature suggest that monitoring and maintaining cerebral oxygenation may improve perioperative neurological outcomes. ${ }^{2,3}$ The NIRS monitor is being used increasingly in the operating room and intensive care unit (ICU) to monitor cerebral perfusion and guide management in various clinical scenarios, which are most established during cardiac surgery. A decrease in cerebral oxygenation correlates with events of clinical deterioration such as arrhythmia, hypotension, and hypoxia. ${ }^{4}$ Changes in cerebral oxygenation have been shown to precede those in pulse oximetry, providing an early detection of clinical deterioration. $^{5}$

In the adult population, alterations in inspired oxygen concentration and expired carbon dioxide have been shown to influence cerebral oxygenation. ${ }^{6}$ Various patient, surgical, and anesthetic factors may influence intraoperative ventilation choices (minute ventilation and the fraction of inspired oxygen $\left.\left[\mathrm{FiO}_{2}\right]\right)$ and the resultant arterial partial pressure of oxygen $\left(\mathrm{PaO}_{2}\right)$ and carbon dioxide $\left(\mathrm{PaCO}_{2}\right){ }^{7-11}$ Examples include laparoscopic surgery, intrathoracic surgery, airway surgery, patient positioning, and comorbid conditions. ${ }^{8,9}$ Furthermore, various factors including a decrease in the metabolic rate related to general anesthesia may result in inadvertent hyperventilation during routine intraoperative care. ${ }^{9}$ Understanding how ventilation affects cerebral oxygenation is of clinical importance, especially when faced with other physiological changes such as anemia and decreased cardiac output that may impact tissue and cerebral oxygen delivery. The relationship between ventilation and cerebral $\mathrm{rSO}_{2}$ has not been examined in the pediatric population. The aim of the current study was to evaluate the changes in cerebral and tissue $\mathrm{rSO}_{2}$ during intraoperative changes in mechanical ventilation parameters.

\section{Patients and methods}

This study was reviewed and approved by the institutional review board (IRB) of Nationwide Children's Hospital. As approved by the IRB, prior to study enrollment, verbal consent from a parent and assent from the patient were obtained. This study was registered with ClinicalTrials.gov (NCT02651103). Enrolled patients were children undergoing a major surgical procedure requiring placement of an arterial cannula. Prior to anesthetic induction, the NIRS monitor was placed on the forehead and over the deltoid muscle, in addition to standard American Society of Anesthesiologist (ASA) monitors. Baseline values for cerebral and tissue oxygenation were obtained using NIRS. After the induction of general anesthesia and placement of an endotracheal tube, an arterial cannula was placed and NIRS values were again measured at the following four phases of ventilation with variation of the inspired oxygen concentration $\left(\mathrm{FiO}_{2}\right)$ and end-tidal carbon dioxide $\left(\mathrm{ETCO}_{2}\right)$ value:

1. Normocarbia $\left(\mathrm{ETCO}_{2}=35-40 \mathrm{mmHg}\right)$ and low $\mathrm{FiO}_{2}(0.3)$

2. Hypocarbia $\left(\mathrm{ETCO}_{2}=25-30 \mathrm{mmHg}\right)$ and low $\mathrm{FiO}_{2}(0.3)$

3. Hypocarbia $\left(\mathrm{ETCO}_{2}=25-30 \mathrm{mmHg}\right)$ and high $\mathrm{FiO}_{2}(0.6)$

4. Normocarbia $\left(\mathrm{ETCO}_{2}=35-40 \mathrm{mmHg}\right)$ and high $\mathrm{FiO}_{2}$ (0.6)

Following the changes in mechanical ventilation for each phase of the study, an equilibration period of 15 min was allowed prior to data collection. To ensure the accuracy of the $\mathrm{ETCO}_{2}$ value, arterial blood gas was obtained prior to the start of the study and the $\mathrm{ETCO}_{2}$ was validated using the $\mathrm{PaCO}_{2}$ measurement. At baseline and during each phase of ventilation, NIRS measurements were recorded every minute over a 5-min period. Heart rate (HR) and BP were recorded at each of the sampling intervals, and hemodynamic variables were maintained constant by adjustments in the continuous infusion of remifentanil. Depth of anesthesia was maintained at a constant value with the administration of inhaled desflurane which was titrated to maintain the bispectral index (BIS) at 50-60.

\section{Statistical analyses}

The average of the available NIRS measurements within each ventilation phase was obtained and used to compare sequential phases with paired $t$-tests. Sequential changes in these outcomes were evaluated using paired $t$-tests. Normal distribution of all the study outcomes at baseline was checked using the Shapiro-Wilk test, and tests of statistical significance at subsequent time points were robust to using nonparametric signed-rank tests. A planned sample size of 30 patients was selected to be comparable with previous studies in the adult population and to be consistent with study feasibility and projected patient enrollment. Due to the exploratory nature of this study in a pediatric population, no a priori power analysis was performed. Data analysis was performed using Stata/IC 13.1 (StataCorp LP, College Station, TX, USA), and two-tailed $p<0.05$ was considered statistically significant. 


\section{Results}

The study cohort included 30 patients (13 males and 17 females, age $15 \pm 3$ years, and weight $55 \pm 15 \mathrm{~kg}$ ). Cohort characteristics are summarized in Table 1 , and the distribution of the study outcomes is shown as a box plot in Figure 1. The peripheral oxygen saturation by pulse oximetry remained at $99 \%-100 \%$ throughout the study. The baseline cerebral and tissue $\mathrm{rSO}_{2}$, prior to anesthetic induction while breathing room air, were $81 \% \pm 9 \%$ and $87 \% \pm 5 \%$, respectively. During phase 1 , cerebral $\mathrm{rSO}_{2}$ was $83 \% \pm 8 \%$, which decreased to $79 \% \pm 8 \%$ in phase 2 (hypocarbia and low $\mathrm{FiO}_{2}$ ). Cerebral oxygenation recovered, returning to baseline values, during phase $3(81 \% \pm 9 \%)$ and phase $4(83 \% \pm 8 \%)$. Each sequential

Table I Study cohort characteristics

\begin{tabular}{ll}
\hline Variables & N (\%) or mean (SD) \\
\hline Gender & \\
$\quad$ Male & $13(43 \%)$ \\
Female & $17(57 \%)$ \\
Age (years) & $15(3)$ \\
Weight (kg) & $55(15)$ \\
ASA status & \\
I & $5(17 \%)$ \\
2 & $16(53 \%)$ \\
3 & $8(27 \%)$ \\
4 & $1(3 \%)$ \\
\hline
\end{tabular}

Abbreviation: ASA, American Society of Anesthesiologist. change (e.g., phase 1 to phase 2 ) in cerebral oxygenation was statistically significant $(p<0.01$; Table 2$)$. Tissue oxygenation increased from $87 \% \pm 8 \%$ in phase 1 to $88 \% \pm 7 \%$ in phase 2 $(p=0.002)$; remained at $88 \% \pm 7 \%$ in phase 3 ; and decreased to $87 \% \pm 8 \%$ in phase 4 ( $p=0.023$; Table 2 ). Changes in HR and BP over the course of the study are summarized in Table 3. There were no statistically significant sequential changes in HR, systolic BP, or diastolic BP over the first three study phases. When comparing phase 4 with phase 3 , slight decreases were noted in HR and BP.

\section{Discussion}

Cerebral oxygenation as measured by NIRS may provide valuable information regarding cerebral oxygen delivery and utilization in critically ill patients in both the operating room and the ICU settings. Intraoperatively, it may help guide anesthetic care, as studies in adults have shown that maintaining adequate values on NIRS may improve neurological outcomes. ${ }^{2,12}$ One of the primary regulators of cerebral blood flow $(\mathrm{CBF})$ is $\mathrm{PaCO}_{2}$. Hypocarbia results in a direct effect on the cerebral vasculature with vasoconstriction and a decrease in CBF. For every $1 \mathrm{mmHg}$ change in $\mathrm{PaCO}_{2}, \mathrm{CBF}$ changes by $1-2 \mathrm{~mL} / 100 \mathrm{~g}$ per minute. As there is no impact on the cerebral metabolic rate for oxygen related to changes in $\mathrm{PaCO}_{2}$, the decrease in $\mathrm{CBF}$ may lead to a decrease in cerebral oxygenation. In our study, cerebral oxygenation as

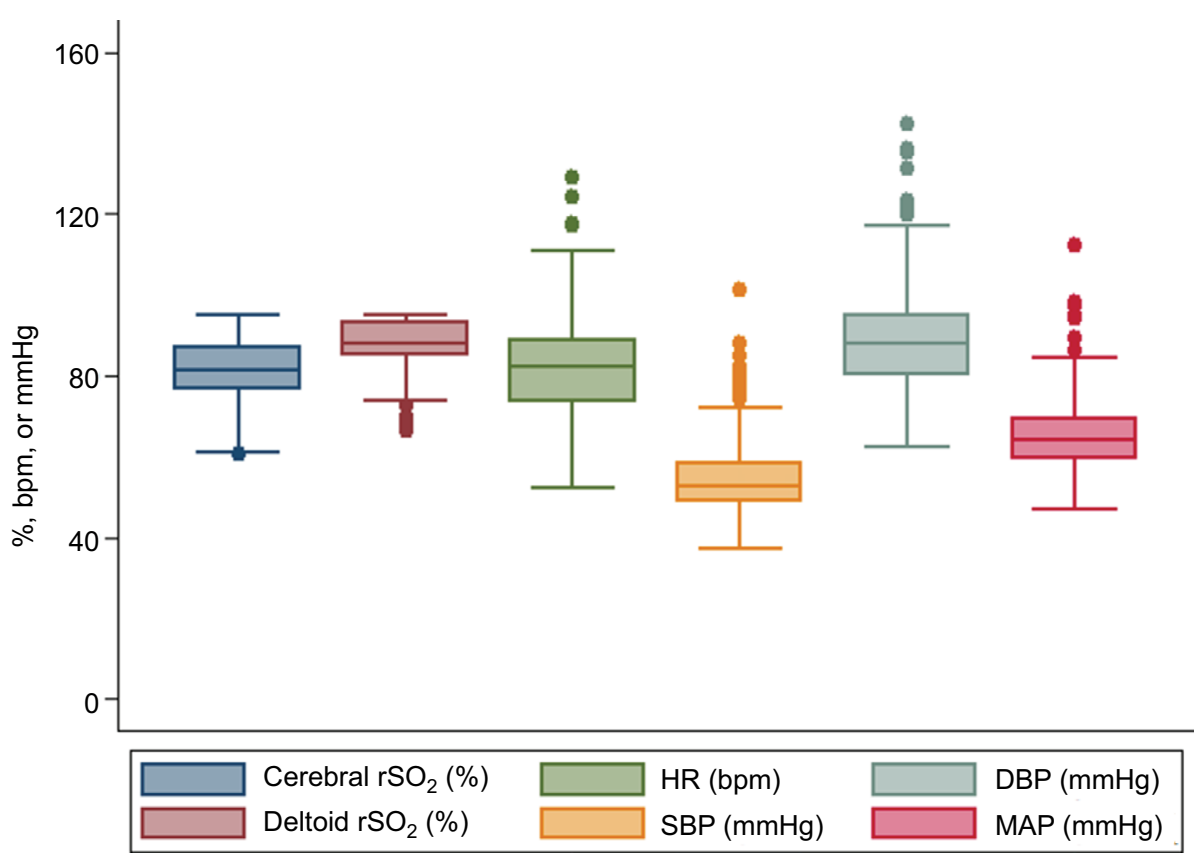

Figure I Box plot of $r \mathrm{SO}_{2}, \mathrm{HR}, \mathrm{SBP}, \mathrm{DBP}$, and mean arterial pressure (MAP) over all the study phases.

Notes: Box center indicates the median, box outline indicates the IQR, box whiskers indicate farthest values within I.5 IQR of the nearest quartile, and scatter points indicate outlier values. $\mathrm{rSO}_{2}$, regional oxygen saturation.

Abbreviations: BP, blood pressure; DBP, diastolic BP; HR, heart rate; IQR, interquartile range; MAP, mean arterial pressure; SBP, systolic BP. 
Table 2 Cerebral and tissue oxygenation during study phases

\begin{tabular}{|c|c|c|c|c|c|c|c|c|}
\hline \multirow{2}{*}{$\begin{array}{l}\mathrm{rSO}_{2} \\
(\%)\end{array}$} & \multicolumn{5}{|c|}{ Study phase } & \multicolumn{3}{|l|}{$p$-value } \\
\hline & Baseline & Phase I & Phase 2 & Phase 3 & Phase 4 & Phase 2 vs. phase I & Phase 3 vs. phase 2 & Phase 4 vs. phase 3 \\
\hline Tissue & $87(5)$ & $87(8)$ & $88(7)$ & $88(7)$ & $87(8)$ & 0.002 & 0.776 & 0.023 \\
\hline Cerebral & $81(9)$ & $83(8)$ & $79(8)$ & $81(9)$ & $83(8)$ & $<0.001$ & 0.007 & 0.009 \\
\hline
\end{tabular}

Notes: $\mathrm{rSO}_{2}$, oxygenation determined by NIRS. Values for $\mathrm{rSO}_{2}$ are presented as mean and SD.

Abbreviations: NIRS, near-infrared spectroscopy.

Table 3 Hemodynamic parameters during the four study phases

\begin{tabular}{|c|c|c|c|c|c|c|c|c|}
\hline \multirow[t]{2}{*}{ Variable } & \multirow[t]{2}{*}{ Baseline } & \multirow[t]{2}{*}{ Phase I } & \multirow[t]{2}{*}{ Phase 2} & \multirow[t]{2}{*}{ Phase 3} & \multirow[t]{2}{*}{ Phase 4} & \multicolumn{3}{|l|}{ p-value } \\
\hline & & & & & & $\begin{array}{l}\text { Phase } 2 \text { vs. } \\
\text { phase I }\end{array}$ & $\begin{array}{l}\text { Phase } 3 \text { vs. } \\
\text { phase } 2\end{array}$ & $\begin{array}{l}\text { Phase } 4 \text { vs. } \\
\text { phase } 3\end{array}$ \\
\hline HR (beats per minute) & $90(16)$ & $82(14)$ & $83(14)$ & $82(13)$ & $78(I I)$ & 0.350 & 0.617 & 0.036 \\
\hline $\mathrm{SBP}(\mathrm{mmHg})$ & $100(22)$ & $87(14)$ & $86(11)$ & $90(11)$ & $87(12)$ & 0.544 & 0.132 & 0.037 \\
\hline $\mathrm{DBP}(\mathrm{mmHg})$ & $62(15)$ & $53(9)$ & $53(9)$ & $55(7)$ & $51(7)$ & 0.919 & 0.313 & $<0.001$ \\
\hline MAP $(\mathrm{mmHg})$ & $73(16)$ & $64(10)$ & $64(9)$ & $66(8)$ & $64(8)$ & 0.985 & 0.251 & 0.005 \\
\hline
\end{tabular}

Note: Values for hemodynamic parameters are presented as mean and SD.

Abbreviations: BP, blood pressure; DBP, diastolic BP; HR, heart rate; MAP, mean arterial pressure; SBP, systolic BP.

measured by NIRS declined during general anesthesia with the transition from normocarbia to hypocarbic conditions. Despite this decrease, no clinical impact would be expected as the starting $\mathrm{rSO}_{2}$ was high, the change with hyperventilation was small, and the resultant value remained well above the reported threshold for concern.

Our data demonstrate that, even in clinically stable patients, $\mathrm{PaCO}_{2}$ remains an important determinant of $\mathrm{CBF}$ and cerebral oxygenation. Changes in CBF related to alterations in intraoperative ventilation may have a greater impact on critically ill patients when other factors which impact $\mathrm{rSO}_{2}$, such as hemoglobin values and cardiac output, may be affected. We have previously noted the potential impact of the combination of anemia, hypotension, and hypocarbia on $\mathrm{rSO}_{2}$, suggesting that close attention to the control of ventilation is important during intraoperative care where inadvertent hyperventilation is commonplace.,13

In addition, these data demonstrate that the cerebral $\mathrm{rSO}_{2}$ decrease related to hypocarbia was reversed by the administration of supplemental oxygen (60\% vs. $30 \%)$. A secondary mechanism that may provide additional protection to decreases in cerebral $\mathrm{rSO}_{2}$ in the current study is the effect of anesthetic agents on cerebral oxygen needs. As general anesthetic agents (volatile anesthetic agents, propofol, barbiturates, and benzodiazepines) decrease the cerebral metabolic rate for oxygen, thereby decreasing oxygen extraction. In clinical scenarios where hyperventilation is required, such as to reduce intracranial pressure when there is impending cerebral herniation or to blunt the respiratory drive, increasing the $\mathrm{FiO}_{2}$ may be pertinent to offset any reduction in cerebral oxygenation related to decreases in CBF. Thiagarajan et al evaluated 18 adults with traumatic brain injury to determine the changes in cerebral jugular venous oxygen saturation $\left(\mathrm{SjvO}_{2}\right)$ and arteriovenous oxygen content difference $\left(\mathrm{AVDO}_{2}\right)$ in response to changes in $\mathrm{PaO}_{2}$ and $\mathrm{PaCO}_{2}{ }^{15} \mathrm{SjvO}_{2}$ decreased from $66 \% \pm 3 \%$ to $56 \% \pm 3 \%$ when $\mathrm{PaCO}_{2}$ decreased from 30 to $25 \mathrm{mmHg}$ at a $\mathrm{PaO}_{2}$ of $100-150 \mathrm{mmHg}$. The $\mathrm{SjvO}_{2}$ values were significantly greater when the $\mathrm{PaO}_{2}$ was $200-250 \mathrm{mmHg}$ (77\% $\pm 4 \%$ and $64 \% \pm 3 \%$ ) at $\mathrm{PaCO}_{2}$ values of both 30 and $25 \mathrm{mmHg}$. The authors concluded, as we did in our study, that decreases in cerebral oxygenation (manifested as decreases in $\mathrm{SjvO}_{2}$ ) associated with a decrease in $\mathrm{PaCO}_{2}$, were offset by increasing the $\mathrm{PaO}_{2}$. These data are particularly relevant given the literature demonstrating episodes of cerebral ischemia and worse neurologic outcome in patients with traumatic brain injury who are exposed to hypocarbia. ${ }^{15}$

Similar results have been noted in the adult population by other investigators using various monitors of cerebral oxygenation. All of these studies have demonstrated that both alterations in inspired oxygen concentration and expired carbon dioxide impact cerebral tissue oxygenation. Tisdall et a ${ }^{6}$ measured the cerebral tissue oxygenation index (TOI) in 15 adults under hypoxic, hyperoxic, and hypo- and hypercarbic conditions. Hypoxemic and hypocarbic conditions resulted in a decrease in the TOI by $7.1 \%$ and $2.1 \%$, respectively, while hyperoxia and hypercarbia led to increases of $2.3 \%$ and $2.6 \%$. Picton et $\mathrm{al}^{10}$ reported a $7 \%$ decrease in $\mathrm{rSO}_{2}$ after beach chair positioning in adults maintained at an $\mathrm{FiO}_{2}$ of 0.3 and $\mathrm{ETCO}_{2}$ of $30 \mathrm{mmHg}$ which was reversible by decreasing ventilation and increasing the $\mathrm{FiO}_{2}$. The same investigators reported that the $\mathrm{rSO}_{2}$ was an average of $8 \%$ higher with an $\mathrm{FiO}_{2}$ of 1.0 vs. 0.3 at an $\mathrm{ETCO}_{2}$ of $30-35 \mathrm{mmHg}$. Bouzat et $\mathrm{al}^{16}$ reported a 
$5 \%$ reduction in $\mathrm{rSO}_{2}$ with hyperventilation in adult patients recovering from cardiac arrest.

Our literature search revealed no previous studies in the pediatric age range that examined the effect of ventilation on cerebral oxygenation. When compared with some of the adult studies, it is not surprising that the decrease in cerebral oxygenation that we noted was smaller than that seen in the adult population, as our patients lacked comorbid conditions, such as atherosclerotic disease, which might affect CBF. When evaluating intraoperative studies, including the current study, one must also consider the impact that the anesthetic agents may have on the findings as specific anesthetic agents may affect cerebral metabolic rate for oxygenation and thereby mitigate the effects of the decrease in CBF on cerebral oxygenation. ${ }^{17}$ As the current study focused on adolescents, extrapolation of these data to younger populations is likely infeasible, and additional trials are needed in these age groups to determine the impact of changes in ventilation on cerebral $\mathrm{rSO}_{2}$.

\section{Conclusion}

No clinically significant changes in tissue oxygenation were noted related to hyperventilation, and the changes in cerebral $\mathrm{rSO}_{2}$ under the specific study conditions had no clinical impact. As $\mathrm{PaCO}_{2}$ did not affect tissue blood flow and had limited impact on cardiac output, changes in tissue oxygenation were minimal with an average value of $87 \%$ or $88 \%$ during all the study phases. The change from baseline of cerebral $\mathrm{rSO}_{2}$ was minimal, and the low value even under hypobaric conditions was well above the NIRS monitor's low threshold value for concern. However, the impact of hypocarbia must be considered when comorbid conditions or ongoing acute issues, such as anemia or hypotension, may further impact cerebral oxygenation. In specific clinical scenarios where hyperventilation is clinically indicated, the impact on cerebral oxygenation can be mitigated by increasing the $\mathrm{FiO}_{2}$.

\section{Acknowledgment}

Preliminary results from this study were presented in abstract form in the American Society of Anesthesiologists Annual Meeting (Chicago, IL, USA; October 2016); Society for Critical Care Medicine Annual Meeting (Honolulu, HI, USA; January 2017); and the Society for Pediatric Anesthesiology Annual Meeting (Austin, TX, USA; March 2017).

\section{Disclosure}

The authors report no conflicts of interest in this work.

\section{References}

1. Tobias JD. Cerebral oxygenation monitoring: near infrared spectroscopy. Expert Rev Med Devices. 2006;3(2):235-243.

2. Casati A, Fanelli G, Pietropaoli P, et al. Continuous monitoring of cerebral oxygen saturation in elderly patients undergoing major abdominal surgery minimizes brain exposure to potential hypoxia. Anesth Analg. 2005;101(3):740-747.

3. Austin EH III, Edmonds HL Jr, Auden SM, et al. Benefit of neurophysiologic monitoring for pediatric cardiac surgery. $J$ Thorac Cardiovasc Surg. 1997;114(5):707-715.

4. Naguib AN, Winch P, Ro PS, Olshove V, Tobias JD. Changes in nearinfrared spectroscopy and the bispectral index during tilt-table examination. Pediatr Cardiol. 2011;32(2):234-236.

5. Tobias JD. Cerebral oximetry monitoring with near infrared spectroscopy detects alterations in oxygenation before pulse oximetry. J Intensive Care Med. 2008;23(6):384-388.

6. Tisdall MM, Taylor C, Tachtsidis I, Leung TS, Elwell CE, Smith M. The effect on cerebral tissue oxygenation index of changes in the concentrations of inspired oxygen and end-tidal carbon dioxide in healthy adult volunteers. Anesth Analg. 2009;109(3):906-913.

7. Rozmiarek A, Taghon T, Tobias JD. Inadvertent hyperventilation during intraoperative anesthetic care in the pediatric population. ICU Director. 2012;4:172-175.

8. Tobias JD, Holcomb GW III, Brock JW III, Deshpande JK, Lowe S, Morgan WM III. Cardiorespiratory changes during laparoscopy in children. J Pediatr Surg. 1995;30(1):33-36.

9. Picton P, Dering A, Alexander A, et al. Influence of ventilation strategies and anesthetic techniques on regional cerebral oximetry in the beach chair position: a prospective interventional study with a randomized comparison of two anesthetics. Anesthesiology. 2015;123(4):765-774.

10. Picton P, Shanks A, Dorje P, Mashour GA. The influence of basic ventilation strategies on cerebral oxygenation in anesthetized patients without vascular disease. J Clin Monit Comput. 2010;24(6):421-425.

11. Booth EA, Dukatz C, Sood BG, Wider M. Near-infrared spectroscopy monitoring of cerebral oxygen during assisted ventilation. Surg Neurol Int. 2011;2:65-68.

12. Murkin JM, Adams SJ, Novick RJ, et al. Monitoring brain oxygen saturation during coronary bypass surgery: a randomized, prospective study. Anesth Analg. 2007;104(1):51-58.

13. Shear T, Tobias JD. Cerebral oxygenation monitoring using near infrared spectroscopy during controlled hypotension. Paediatr Anaesth. 2005;15(6):504-508.

14. Skippen P, Seear M, Poskitt K, et al. Effect of hyperventilation on regional cerebral blood flow in head-injured children. Crit Care Med. 1997;25(8):1402-1409.

15. Thiagarajan A, Goverdhan PD, Chari P, Somasunderam K. The effect of hyperventilation and hyperoxia on cerebral venous oxygen saturation in patients with traumatic brain injury. Anesth Analg. 1998;87(4):850-853.

16. Bouzat P, Suys T, Sala N, Oddo M. Effect of moderate hyperventilation and induced hypertension on cerebral tissue oxygenation after cardiac arrest and therapeutic hypothermia. Resuscitation. 2013;84(11): $1540-1545$.

17. Ishiyama T, Kotoda M, Asano N, et al. Effects of hyperventilation on cerebral oxygen saturation estimated using near-infrared spectroscopy: a randomised comparison between propofol and sevoflurane anaesthesia. Eur J Anaesthesiol. 2016;33(12):929-935. 


\section{Publish your work in this journal}

Medical Devices: Evidence and Research is an international, peerreviewed, open access journal that focuses on the evidence, technology, research, and expert opinion supporting the use and application of medical devices in the diagnosis, monitoring, treatment and management of clinical conditions and physiological processes. The identification of novel devices and optimal use of existing devices which will lead to improved clinical outcomes and more effective patient management and safety is a key feature. The manuscript management system is completely online and includes a quick and fair peer-review system. Visit http://www. dovepress.com/testimonials.php to read real quotes from authors.

Submit your manuscript here: https://www.dovepress.com/medical-devices-evidence-and-research-journal 